\title{
The effect of perioperative insulin treatment on cardiodepression in mild adiposity in mice
}

\author{
Chantal A. Boly ${ }^{1,2^{*}}$, Etto C. Eringa ${ }^{2}$, R. Arthur Bouwman ${ }^{3}$, Rob F. P. van den Akker ${ }^{1,2}$, Frances S. de Man², \\ Ingrid Schalij ${ }^{2,4}$, Stephan A. Loer ${ }^{1}$, Christa Boer ${ }^{1}$ and Charissa E. van den Brom,2
}

\begin{abstract}
Background: While most studies focus on cardiovascular morbidity following anesthesia and surgery in excessive obesity, it is unknown whether these intraoperative cardiovascular alterations also occur in milder forms of adiposity without type 2 diabetes and if insulin is a possible treatment to improve intraoperative myocardial performance. In this experimental study we investigated whether mild adiposity without metabolic alterations is already associated with cardiometabolic dysfunction during anesthesia, mechanical ventilation and surgery and whether these myocardial alterations can be neutralized by intraoperative insulin treatment.
\end{abstract}

Methods: Mice were fed a western (WD) or control diet (CD) for 4 weeks. After metabolic profiling, mice underwent general anesthesia, mechanical ventilation and surgery. Cardiac function was determined with echocardiography and left-ventricular pressure-volume analysis. Myocardial perfusion was determined with contrast-enhanced echocardiography. WD-fed mice were subsequently treated with insulin by hyperinsulinemic euglycemic clamping followed by the same measurements of cardiac function and perfusion.

Results: Western-type diet feeding led to a $13 \%$ increase in bodyweight, $(p<0.0001)$ and increased adipose tissue mass, without metabolic alterations. Despite this mild phenotype, WD-fed mice had decreased systolic and diastolic function (end-systolic elastance was $2.0 \pm 0.5$ versus $4.1 \pm 2.4 \mathrm{mmHg} / \mu \mathrm{L}, p=0.01$ and diastolic beta was $0.07 \pm 0.03$ versus $0.04 \pm 0.01 \mathrm{mmHg} / \mu \mathrm{L}, \mathrm{p}=0.02$ ) compared to $\mathrm{CD}$-fed mice. Ventriculo-arterial coupling and myocardial perfusion were decreased by $48 \%(p=0.003)$ and $43 \%(p=0.03)$ respectively. Insulin treatment in WD-fed mice improved echo-derived systolic function (fractional shortening $42 \pm 5 \%$ to $46 \pm 3, p=0.05$ ), likely due to decreased afterload, but there was no effect on load-independent measures of systolic function or myocardial perfusion. However, there was a trend towards improved diastolic function after insulin treatment ( $43 \%$ improvement, $p=0.05$ ) in WD-fed mice.

Conclusions: Mild adiposity without metabolic alterations already affected cardiac function and perfusion during anesthesia, mechanical ventilation and surgery in mice. Intraoperative insulin may be beneficial to reduce afterload and enhance intraoperative ventricular relaxation, but not to improve ventricular contractility or myocardial perfusion.

Keywords: Insulin, Myocardial contraction, Myocardial perfusion, Adiposity, Perioperative period

\footnotetext{
*Correspondence: c.boly@vumc.nl

1 Department of Anesthesiology, Institute for Cardiovascular Research,

VU University Medical Center, De Boelelaan 1117, 1081 HV Amsterdam,

The Netherlands

Full list of author information is available at the end of the article
} 


\section{Background}

Adiposity is a characteristic of about $50 \%$ of patients undergoing anesthesia and surgery [1], and a risk factor for the development of cardiovascular complications in the perioperative setting. On one hand this is due to the presence of systolic and diastolic dysfunction, in part caused by elevated cardiac output, increased left-ventricular (LV) wall stress and cardiac hypertrophy [2]. On the other hand, increased adiposity is associated with decreased coronary flow reserve, which is indicative of impaired myocardial perfusion [3]. Moreover, the metabolic and cardiovascular alterations in the overweight conditions may influence response to analgesia, anesthetics, mechanical ventilation and surgical stress $[4$, 5]. Clinical studies focusing on the impact of anesthesia, mechanical ventilation and surgery on myocardial function frequently focus on morbid obesity, while milder forms of increased adiposity are neglected as risk factor in the perioperative setting. However, even milder forms of obesity and the metabolic syndrome are associated with a higher incidence of postoperative morbidity, including cardiac events [6]. In obese, non-diabetic rats, adrenergicmediated hemodynamic effects were distinctly affected by the volatile anesthetic isoflurane when compared to nonobese rats [7]. Moreover, diet-induced obesity in rats is associated with systolic dysfunction and myocardial perfusion disturbances when compared to lean animals, and sevoflurane anesthesia further aggravates this myocardial contractile response [8]. Since these animal studies suggest that even non-diabetic adiposity is associated with hemodynamic and cardiovascular disturbances in the perioperative period, more insight in the pathophysiology as well as possible treatment strategies are warranted.

In order to gain insight in the impact of mild adiposity on myocardial function during anesthesia and surgery, we investigated whether mild adiposity without metabolic alterations is already associated with intraoperative alterations in myocardial function in an experimental mouse model. We further hypothesized that mild adiposity is associated with cardiovascular alterations that can be restored by perioperative insulin treatment. Insulin has positive inotropic effects and it is known that high dose insulin improves cardiac function in animals with septic and hemorrhagic shock $[9,10]$ but also in patients undergoing cardiac surgery [11].

\section{Methods}

\section{Animals}

Animal experiments were approved by the Institutional Animal Care and Use Committee of the VU University (Amsterdam, the Netherlands. Permit number: ANES 12-04/ANES 13-04), and were conducted following the European Convention for the Protection of Vertebrate
Animals used for Experimental and Other Scientific Purposes and the ARRIVE guidelines on animal research [12]. Five week old male C57BL/6J obtained from Charles River Laboratories mice were housed in a temperaturecontrolled room $\left(20-23{ }^{\circ} \mathrm{C}\right.$; $40-60 \%$ humidity) under a $12 / 12 \mathrm{~h}$ light/dark cycle starting at $6.00 \mathrm{am}$. Body weight was determined on a weekly basis. After 4 weeks of western-type diet feeding an oral glucose tolerance test was performed and mice subsequently underwent the in vivo protocol consisting of left ventricular (LV) pressure-volume measurements and (contrast-) echocardiography under anesthesia. At the end of the experiment, mice were euthanized by heart excision under anesthesia.

\section{Adiposity model and metabolic profiling}

Mice were randomized into a group fed a western-type diet (D12079B, Research Diets New Brunswick, NJ) consisting of $17 \% \mathrm{kcal}$ protein, $43 \% \mathrm{kcal}$ carbohydrates and $41 \% \mathrm{kcal}$ fat, ad libitum for 4 weeks. The control group was fed a normal chow diet (Teklad 2016, Harlan, Horst, the Netherlands) with $16 \% \mathrm{kcal}$ protein, $4 \% \mathrm{kcal}$ fat and $80 \% \mathrm{kcal}$ carbohydrates for 4 weeks.

An oral glucose tolerance test (OGTT) was performed after 4 weeks of diet exposure. After overnight fasting, conscious mice received a bolus of glucose $(2 \mathrm{~g} / \mathrm{kg})$ via oral gavage. Blood was drawn from a tail-cut immediately before glucose challenge and at 15, 30, 60, 90 and $120 \mathrm{~min}$ thereafter using a Precision Xceed Blood Glucose monitoring system (MediSense, UK). The area under the blood glucose curve (AUC) was used to compare glucose tolerance between western-type and control diet-fed mice.

In mice that had only undergone baseline measurements and no insulin treatment, blood was drawn from the right ventricle of the heart and plasma concentrations of fasting insulin, free fatty acids and triglycerides were measured using commercial ELISA and enzymatic measurement kits according to the manufacturer (LINCO research, St. Charles, MO; WAKO NEFA-C, Wako Pure Chemical Industries, Osaka, Japan).

\section{Anesthesia and mechanical ventilation}

After 4 weeks of diet exposure, anesthesia was induced with fentanyl $0.5 \mathrm{mg} / \mathrm{kg}$, midazolam $9.4 \mathrm{mg} / \mathrm{kg}$ and acepromazine $9.4 \mathrm{mg} / \mathrm{kg}$ injected intraperitoneally. Anesthesia was maintained by continuous intravenous infusion of fentanyl $0.1 \mathrm{mg} / \mathrm{kg} / \mathrm{h}$, midazolam $2.3 \mathrm{mg} / \mathrm{kg} / \mathrm{h}$ and acepromazine $2.3 \mathrm{mg} / \mathrm{kg} / \mathrm{h}$ via a $26 \mathrm{G}$ cannula in the tail vein. The trachea was intubated and the lungs were mechanically ventilated (maximal pressure $12-14 \mathrm{~cm} \mathrm{H}_{2} \mathrm{O}$; positive end-expiratory pressure, 2-4 $\mathrm{cm} \mathrm{H}_{2} \mathrm{O}$; respiratory rate 150 breaths/min) with oxygen-enriched air $(40 \%$ $\mathrm{O}_{2} / 60 \% \mathrm{~N}_{2}$ ). Body temperature was maintained at $37{ }^{\circ} \mathrm{C}$ using a body-temperature controlled heating pad. 


\section{Surgery and monitoring}

A catheter was placed in the right jugular vein for infusion of contrast agent, insulin and/or glucose. The left carotid artery was cannulated for measurements of arterial blood pressure (Safedraw Transducer Blood Sampling Set, Argon Medical Devices, Texas, USA). Arterial blood pressure, ECG, heart rate and temperature were continuously recorded using PowerLab software (PowerLab 8/35, Chart 8.0; ADInstruments Pty, Ltd., Castle Hill, Australia).

\section{Experimental protocol}

After induction of anesthesia and cannulation of veins and arteries, mice underwent different experimental protocols, which are depicted in Fig. 1. (Contrast-enhanced) echocardiography measurements at baseline and during insulin treatment were paired (group A). However, pressure-volume loop measurements could not be paired due to the invasive nature of insertion of the Millar catheter in the LV (group B, C).

\section{(Contrast-enhanced) echocardiography}

(Contrast-enhanced) echocardiography was performed using a Siemens (ACUSON, Sequoia 512) device equipped with a $14 \mathrm{MHz}$ linear array transducer as described previously $[8,13]$. Before infusion of contrast agent, contractile function was determined by visualizing the LV in short axis midpapillary view, and left ventricular end-systolic (ESD) and end-diastolic (EDD) diameters were determined in M-mode. LV systolic function is represented by fractional shortening (FS) which was calculated by the following equation: $\mathrm{FS}=(\mathrm{EDD}-\mathrm{ESD}) / \mathrm{EDD} \cdot 100)$. All parameters were averaged over at least three cardiac contractile cycles. A typical example of echocardiography windows in control versus western diet-fed mice is shown in Fig. 2, upper part of panels a and b.

Contrast-echocardiography was performed as previously described $[8,13,14]$. Briefly, perfluorbutane filled

\begin{tabular}{|l|l|}
\hline \multicolumn{1}{|c|}{ Baseline } & \multicolumn{1}{c|}{ Insulin } \\
(a) $\begin{array}{l}\text { Contrast-enhanced } \\
\text { echocardiography }\end{array}$ & $\begin{array}{l}\text { Contrast-enhanced } \\
\text { echocardiography }\end{array}$ \\
b $\begin{array}{l}\text { Left-ventricle pressure- } \\
\text { volume loop analysis }\end{array}$ & \\
(C) & $\begin{array}{l}\text { Left-ventricle pressure- } \\
\text { volume loop analysis }\end{array}$ \\
Fig. 1 Experimental protocol. After induction of anesthesia and \\
cannulation of vessels mice underwent contrast-enhanced echo- \\
cardiography at baseline and after insulin treatment (group $A$ ), or \\
pressure-volume loop analysis at baseline (group $B$ ) and after insulin \\
treatment (group $C$ )
\end{tabular}
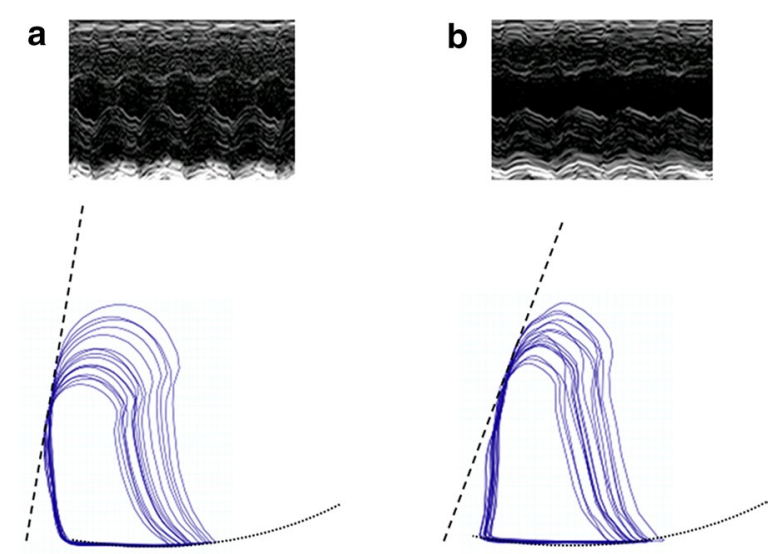

Fig. 2 Typical examples of echocardiography and pressure-volume loops measurements in control (a) and western diet-fed (b) mice. Echocardiography windows are short axis midpapillary views which where used for estimation of fractional shortening, and demonstrated pressure volume loops were used for estimation of endsystolic (striped line) and end-diastolic (dotted line) pressure-volume relation estimations and related parameters

microbubbles were continuously infused into the jugular vein and visualized in midpapillary short-axis views of the LV. After two minutes of microbubble infusion, perfusion recordings were taken with low acoustic power (mechanical index [MI] 0.19) for microbubble detection with a dynamic range of $50 \mathrm{~dB}$, followed by a burst of high acoustic power (MI 1.8) for complete contrast destruction. Subsequently, on average 80 cardiac cycles of low MI images were acquired to allow contrast replenishment in the myocardium. All data were stored for offline analysis.

Custom-designed software was used for analysis of the estimate of myocardial perfusion (Matlab, 7.10, R2010A, MathWorks Inc. MA, USA) [14]. For each cardiac cycle, regions of interest were drawn in the end-systolic frame in the short axis view of the LV myocardium. Signal intensities from the frames after microbubble destruction were corrected for background noise by subtracting the signal intensity of the first frame after microbubble destruction $\left(\mathrm{Y}_{0}\right)$. These intensities were then fitted $\left[\mathrm{Y}=\mathrm{Y}_{0}+\left(A-\mathrm{Y}_{0}\right) \cdot\left(1-\exp ^{(-\beta} \cdot{ }^{\mathrm{x}}\right)\right]$ for calculation of microvascular blood volume $A$ and the microvascular filling velocity $B$, which corresponds to the capillary blood exchange rate. The estimate of myocardial perfusion was calculated as the product of $A$ and $B$.

\section{Pressure-volume loops}

After induction of anesthesia a subcostal thoracotomy was performed and a pressure-volume Millar catheter (SPR 869, Millar Instruments, Houston, TX) was inserted in the LV via the apex. The Millar catheter 
continuously measures pressure and volume in the LV, and the volume signal was calibrated with stroke volume estimations that were obtained with echocardiography in the closed-chest situation. A ligature was placed under the inferior vena cava for transient preload reductions. Pressure-volume loops were measured in three series with vena cava occlusion-induced preload reduction. In a different group of mice, the same measurements were performed after hyperinsulinemic euglycemic clamping. Analysis of pressure volume loops was performed using PowerLab software (PowerLab 8/35, Chart 8.0; ADInstruments Pty, Ltd., Castle Hill, Australia). From steady state measurements, LV mean and end-systolic pressures as well as arterial elastance $\left(E_{a}\right)$, a measure for left ventricular afterload, were determined. From vena cava occlusion data, end-systolic elastance $\left(E_{e s}\right)$ was determined as the slope of the end-systolic pressure-volume relationship, a load-independent measure for cardiac contractility. The slope of the end-diastolic pressurevolume relationship, Beta, was determined, which is considered a load-independent determinant of diastolic function. The ratio $\mathrm{E}_{\mathrm{es}} / \mathrm{E}_{\mathrm{a}}$ was determined as an estimate of ventriculo-arterial coupling, which describes adaptation of the LV in relation to the vasculature [15]. Typical examples of pressure-volume loops measurements during vena cava occlusion and related end-systolic and end-diastolic pressure-volume relations in control versus western-diet fed mice are shown in Fig. 2, the bottom of panels $a$ and $b$.

\section{Insulin treatment}

For insulin treatment with maintenance of euglycemic conditions, a hyperinsulinemic clamp was performed as described [16] after overnight fasting and under anesthesia. After determination of baseline glucose level a bolus of $100 \mathrm{mU} / \mathrm{kg}$ insulin was administered intravenously over $2 \mathrm{~min}$ followed by continuous infusion of insulin at a rate of $3 \mathrm{mU} / \mathrm{kg} / \mathrm{min}$ for $60 \mathrm{~min}$. Blood glucose levels were determined at intervals of $5 \mathrm{~min}$ and glucose infusion ( $20 \%$ glucose diluted in $\mathrm{NaCl}$ ) was adjusted to maintain euglycemia. After 60 min a steady state of euglycemia was achieved and mice were otherwise excluded from analysis.

\section{Data analysis}

All data are presented as mean and standard deviation (SD). Statistical differences between the western-type diet and the control group were tested using a Student $t$ test or two-way ANOVA for variables with multiple time points. The difference between insulin-stimulated conditions and the baseline condition in the obese group were tested with paired or Student $t$ tests. A $p<0.05$ was considered as statistically significant.

\section{Results}

\section{Mild adiposity model}

Characteristics of mice fed a control or western diet for 4 weeks are shown in Table 1 . Western diet (WD) feeding led to an increase in caloric intake of almost $20 \%$ compared to chow diet $(\mathrm{p}<0.0001)$, which resulted in $13 \%$ higher bodyweight $(\mathrm{p}<0.0001)$ compared to controls and higher heart- and fatpad weights. There was no hyperglycemia, hyperinsulinemia or hyperlipidemia as determined under fasting conditions. Furthermore, an oral glucose tolerance test and hyperinsulinemic euglycemic clamp revealed the absence of glucose intolerance (area under the curve was $1823 \pm 156$ versus $1549 \pm 68$ in control mice, $\mathrm{p}=0.13$ ) and whole body insulin resistance (glucose infusion rate during hyperinsulinemic clamp was $24 \pm 3$ in WD-fed mice versus $25 \pm 2 \mathrm{mg} / \mathrm{min} / \mathrm{kg}$ in control mice, $\mathrm{p}=0.73$ ).

\section{Mild adiposity does not alter hemodynamics}

Hemodynamics as measured under stable, anesthetized conditions are described in Table 2. Under anesthesia, there was no difference in mean arterial pressure between WD- and CD-fed mice $(61 \pm 19$ versus $66 \pm 17 \mathrm{mmHg}$

\section{Table 1 Metabolic characteristics of control and WD-fed} mice

\begin{tabular}{|c|c|c|c|}
\hline & Control & WD-fed & $p$ value \\
\hline Body weight (g) & $23.8 \pm 0.8$ & $27.0 \pm 1.2$ & $<0.0001^{*}$ \\
\hline Tibia length $(\mathrm{mm})$ & $17.2 \pm 0.4$ & $17.1 \pm 0.4$ & 0.66 \\
\hline Caloric intake (g/kg/week) & $3.2 \pm 0.1$ & $3.8 \pm 0.2$ & $<0.0001^{*}$ \\
\hline $\begin{array}{l}\text { Non-fasting blood glucose } \\
(\mathrm{mmol} / \mathrm{L})\end{array}$ & $11.5 \pm 1.9$ & $11.8 \pm 1.8$ & 0.47 \\
\hline Fasting blood glucose (mmol/L) & $6.2 \pm 0.8$ & $5.7 \pm 0.6$ & 0.18 \\
\hline Heart weight (mg) & $103.1 \pm 4.0$ & $127.4 \pm 16.0$ & $0.01^{*}$ \\
\hline Left ventricular weight (mg) & $79.5 \pm 4.1$ & $102.0 \pm 15.8$ & $0.001^{*}$ \\
\hline Right ventricular weight (mg) & $19.1 \pm 2.7$ & $20.8 \pm 4.0$ & 0.34 \\
\hline Epididymal adipose tissue (mg) & $184.3 \pm 32.3$ & $308.0 \pm 119.1$ & $0.01^{*}$ \\
\hline Perirenal adipose tissue (mg) & $50.8 \pm 10.2$ & $84.5 \pm 48.1$ & 0.07 \\
\hline Epicardial adipose tissue (mg) & $2.4 \pm 1.0$ & $7.2 \pm 6.3$ & 0.05 \\
\hline Plasma insulin (ng/mL) & $2.71 \pm 1.31$ & $3.16 \pm 1.06$ & 0.85 \\
\hline Plasma triglycerides (ng/mL) & $0.48 \pm 0.05$ & $0.55 \pm 0.07$ & 0.40 \\
\hline $\begin{array}{l}\text { Plasma free fatty acids } \\
(\mathrm{nmol} / \mathrm{mL})\end{array}$ & $0.09 \pm 0.02$ & $0.09 \pm 0.02$ & 0.51 \\
\hline Oral glucose tolerance test AUC & $1549 \pm 68$ & $1823 \pm 156$ & 0.13 \\
\hline \multicolumn{4}{|l|}{ Hyperinsulinemic euglycemic clamp } \\
\hline $\begin{array}{l}\text { Steady state blood glucose } \\
(\mathrm{mmoll} / \mathrm{L})\end{array}$ & $5.4 \pm 0.2$ & $5.6 \pm 0.2$ & 0.42 \\
\hline $\begin{array}{l}\text { Glucose infusion rate } \\
(\mathrm{mg} / \mathrm{min} / \mathrm{kg})\end{array}$ & $25 \pm 2.2$ & $24 \pm 2.8$ & 0.73 \\
\hline
\end{tabular}

Metabolic characteristics of control and WD-fed mice. AUC area under the curve. Data are presented as mean $\pm S D$ and $n=8-12$ per group. Data were analyzed using a Student's t test for between-group comparisons and 2-way ANOVA with repeated measurements for the oral glucose tolerance test (OGTT) 
Table 2 Baseline hemodynamics for control and WD-fed mice

\begin{tabular}{lccl}
\hline & Control & WD-fed & p value \\
\hline Mean arterial pressure $(\mathrm{mmHg})$ & $66 \pm 17$ & $61 \pm 19$ & 0.34 \\
Heart rate $(\mathrm{BPM})$ & $604 \pm 120$ & $670 \pm 65$ & 0.18 \\
Stroke volume $(\mathrm{HL})$ & $45 \pm 11$ & $36 \pm 7$ & 0.07 \\
Cardiac output $(\mathrm{mL} / \mathrm{min})$ & $26.8 \pm 8.4$ & $24.4 \pm 3.6$ & 0.46 \\
End-systolic pressure $(\mathrm{mmHg})$ & $67 \pm 16$ & $61 \pm 19$ & 0.46 \\
\hline
\end{tabular}

Data are presented as mean $\pm S D$ and $n=6-12$ per group. Student $t$ test, ${ }^{*} \mathrm{p}<0.05$

in control mice, $\mathrm{p}=0.34$ ). Furthermore, although stroke volume showed a trend towards lower values in WD-fed mice (36 \pm 2 versus $45 \pm 4 \mu \mathrm{L}$ in control mice $\mathrm{p}=0.07)$, cardiac output was unaltered compared to controls.

\section{Mild adiposity impairs cardiac function and perfusion} Cardiac function and perfusion parameters are described in Table 3. WD-feeding resulted in decreased systolic function as determined with echocardiography (fractional shortening $43 \pm 6 \%$ versus $56 \pm 8 \%, \mathrm{p} \leq 0.0001$ ) as well as an almost $50 \%$ decrease in pressure-volume loop-derived end-systolic elastance $\left(\mathrm{E}_{\mathrm{es}}\right.$ was $2.0 \pm 0.5$ versus $4.1 \pm 2.4 \mathrm{mmHg} / \mu \mathrm{L}, \mathrm{p}=0.01)$ compared to $\mathrm{CD}$ feeding. Afterload $\left(E_{a}\right)$ did not differ between groups. Ventriculo-arterial coupling $\left(\mathrm{E}_{\mathrm{es}} / \mathrm{E}_{\mathrm{a}}\right)$ was diminished in WD-fed mice compared to controls (coupling ratio was $1.3 \pm 0.6$ versus $2.5 \pm 1.4$ in control mice, $\mathrm{p}=0.003$ ) Furthermore, WD-feeding increased diastolic Beta $(0.07 \pm 0.03$ versus $0.04 \pm 0.01 \mathrm{mmHg} / \mu \mathrm{L}, \mathrm{p}=0.02)$

Table 3 Myocardial function and perfusion parameters in WD-fed mice compared to controls

\begin{tabular}{|c|c|c|c|}
\hline & Control & WD-fed & $p$ value \\
\hline Fractional shortening (\%) & $56 \pm 8$ & $43 \pm 6$ & $<0.0001^{*}$ \\
\hline $\begin{array}{l}\text { End-systolic elastance } \\
\qquad\left(\mathrm{E}_{\mathrm{es}} ; \mathrm{mmHg} / \mu \mathrm{L}\right)\end{array}$ & $4.1 \pm 2.4$ & $2.0 \pm 0.5$ & $0.01^{*}$ \\
\hline $\begin{array}{l}\text { Arterial elastance } \\
\quad\left(\mathrm{E}_{\mathrm{a}} ; \text { afterload; } \mathrm{mmHg} / \mu \mathrm{L}\right)\end{array}$ & $1.6 \pm 0.4$ & $1.8 \pm 0.9$ & 0.51 \\
\hline $\begin{array}{l}\text { Ventriculo-arterial coupling } \\
\qquad\left(\mathrm{E}_{\mathrm{es}} / \mathrm{E}_{\mathrm{a}} \text { ratio }\right)\end{array}$ & $2.5 \pm 1.4$ & $1.3 \pm 0.6$ & $0.003^{*}$ \\
\hline $\begin{array}{l}\text { Beta (diastolic stiffness; } \\
\text { mmHg/ } \mu \mathrm{L})\end{array}$ & $0.04 \pm 0.01$ & $0.07 \pm 0.03^{*}$ & $0.02 *$ \\
\hline \multicolumn{4}{|l|}{ Myocardial perfusion } \\
\hline $\begin{array}{l}\text { Microvascular flow velocity } \\
\beta\left(\mathrm{sec}^{-1}\right)\end{array}$ & $0.49 \pm 0.20$ & $0.59 \pm 0.30$ & 0.24 \\
\hline $\begin{array}{l}\text { Microvascular blood volume } \\
\text { A (A.U.) }\end{array}$ & $0.014 \pm 0.006$ & $0.008 \pm 0.005^{*}$ & $0.006^{*}$ \\
\hline $\begin{array}{l}\text { Estimate of myocardial } \\
\text { perfusion }(A \times \beta)\end{array}$ & $0.007 \pm 0.005$ & $0.004 \pm 0.003^{*}$ & $0.03^{*}$ \\
\hline
\end{tabular}

compared to controls, which implies a stiffer ventricle. Myocardial perfusion was decreased by $43 \%$ in WD-fed mice compared to CD-fed mice $(\mathrm{p}=0.03)$.

\section{Insulin treatment improves diastolic function in mildly adipose mice}

Hemodynamics and cardiac responses to insulin treatment in WD-fed mice are described in Table 4 and visualized in Fig. 3. After $1 \mathrm{~h}$ of insulin treatment, euglycemia was maintained at $5.6 \pm 0.17 \mathrm{mmol} / \mathrm{L}$. Mean arterial blood pressure and cardiac output remained unaltered during insulin treatment, despite a decrease in heart rate. However, insulin decreased end-systolic pressure (61 $\pm 19 \mathrm{mmHg}$ to $43 \pm 8 \mathrm{mmHg}, \mathrm{p}=0.03)$, and there was a trend towards lower afterload $\left(\mathrm{E}_{\mathrm{a}}\right.$ decreased from $1.8 \pm 0.9$ to $1.2 \pm 0.4 \mathrm{mmHg} / \mu \mathrm{L}, \mathrm{p}=0.07$ ) during insulin treatment. While systolic echocardiographic parameters improved slightly in WD-fed mice during insulin treatment (fractional shortening increased from $42 \pm 5 \%$ to $46 \pm 3, p=0.05)$, there was no improvement in end-systolic elastance $\left(\mathrm{E}_{\mathrm{es}}\right.$ was $1.6 \pm 0.3$ versus $2.0 \pm 0.1 \mathrm{mmHg} /$ $\mu \mathrm{L}$ at baseline) nor in ventriculo-arterial coupling. Furthermore, there was a trend towards decreased Beta during insulin treatment $(-43 \%$ from $0.07 \pm 0.01$ to $0.04 \pm 0.01 \mathrm{mmHg} / \mu \mathrm{L} \mathrm{p}=0.05)$, indicating improved diastolic function. Finally, myocardial perfusion was unaffected by insulin treatment in WD-fed mice.

\section{Discussion}

In this study we demonstrated that a mild, early stage of diet-induced adiposity is already associated with decreased systolic and diastolic function, diminished ventriculo-arterial coupling and impaired myocardial perfusion during anesthesia, mechanical ventilation and surgery in mice. In this phenotype, intraoperative insulin treatment improved echo-derived systolic function, decreased afterload and showed a trend towards improved diastolic function. However, there was no effect on load-independent measurements of systolic

Table 4 Hemodynamic response during insulin treatment in WD-fed animals

\begin{tabular}{lccc}
\hline & Baseline & $\begin{array}{c}\text { After insulin } \\
\text { treatment }\end{array}$ & p value \\
\hline $\begin{array}{l}\text { Mean arterial pressure } \\
(\mathrm{mmHg})\end{array}$ & $61 \pm 19$ & $63 \pm 12$ & 0.91 \\
Heart rate (BPM) & $669 \pm 65$ & $593 \pm 73$ & $0.045^{*}$ \\
$\begin{array}{l}\text { Stroke volume }(\mu \mathrm{L}) \\
\text { Cardiac output }(\mathrm{mL} / \mathrm{min})\end{array}$ & $24.4 \pm 3.6$ & $23.1 \pm 6.4$ & 0.45 \\
$\begin{array}{l}\text { End-systolic pressure } \\
\text { (mmHg) }\end{array}$ & $61 \pm 19$ & $43 \pm 18$ & 0.58 \\
\hline
\end{tabular}

Data are presented as mean $\pm S D$ and $n=7-10$ per group. Student $t$ test, ${ }^{*} p<0.05$ 


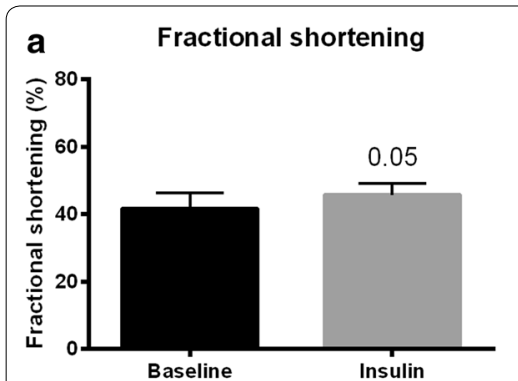

b Ventriculo-arterial coupling

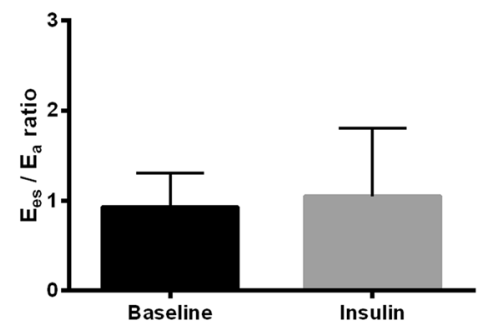

C Microvascular filling velocity $\beta$

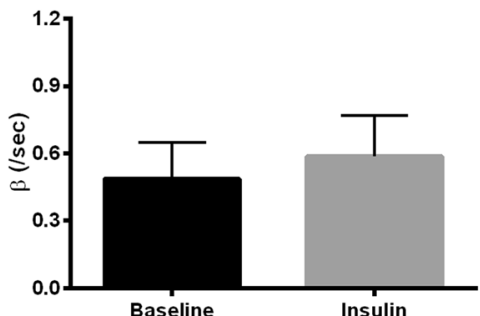

End-systolic elastance

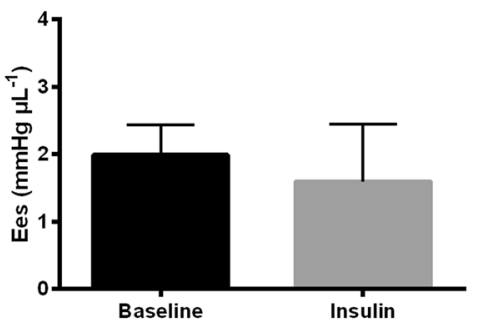

Diastolic stiffness (Beta)

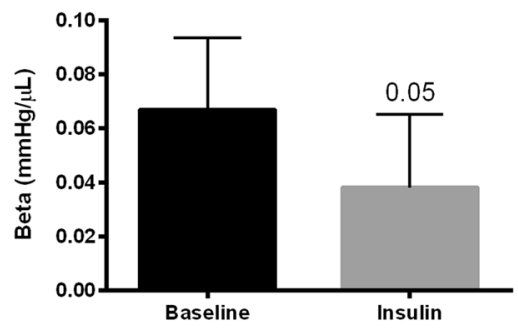

Microvascular blood volume $A$

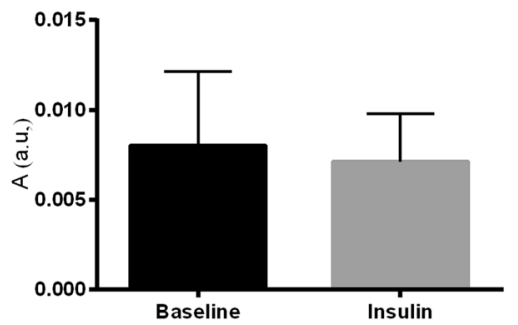

Arterial elastance

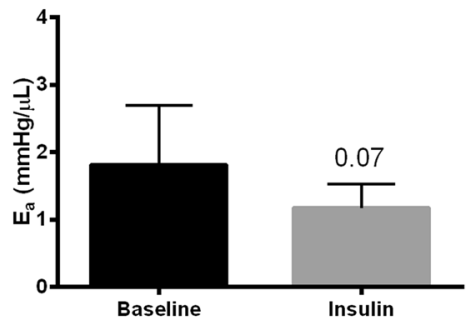

Baseline

Fig. 3 Cardiac function and perfusion response to insulin treatment in WD-fed mice. Cardiac systolic (a), and diastolic (b) function and perfusion (c) responses to insulin treatment. Data are mean $\pm S D$ and $n=7-10$ per group. Paired $t$ test for perfusion-related parameters, Student $t$ test for other parameters, ${ }^{*} p<0.05$

function or myocardial perfusion. These combined findings suggest mild adiposity already compromises cardiac function during anesthetized and mechanically ventilated conditions, and that intraoperative insulin treatment may be applied to positively modulate loading conditions and ventricular relaxation, but not to influence cardiac contractility.

\section{Mild obesity is associated with intraoperative myocardial depression}

In the present study we timed diet exposure to induce an early stage of adiposity without insulin resistance, so that the effect of early overweight conditions without confounding metabolic alterations could be studied. We demonstrated that intraoperative myocardial depression is already present in this early stage. Therefore, mildly adipose patients may be at increased risk for perioperative cardiac alterations, even when presenting in the early stage without metabolic alterations.
In literature, conflicting results have been reported regarding the effect of diet-induced adiposity on systolic function. Some report decreased $[8,13,17,18]$ others unchanged [19] or even improved [20] systolic function. Studies on cardiac function in obesity in the perioperative setting are rare, but have shown additional cardiodepressive effects of sevoflurane in diet-induced obese rats [8]. In our mild phenotype we found impaired fractional shortening but also load-independent end-systolic elastance, indicating that this is a true contractility effect. Decreased ventriculo-arterial coupling furthermore indicates inadequate adaptation of the heart to the vasculature. Importantly, exposure to general anesthesia and mechanical ventilation in combination with surgical stress in our study, may have exacerbated subclinical systolic dysfunction that would otherwise remain undetected.

Diastolic dysfunction is a consistent finding in dietinduced adiposity, and is the predominant cardiac feature in earlier stages of human obesity [2]. The increased 
slope of the end-diastolic pressure-volume relation in our study indicates increased ventricular stiffness, which is a finding consistent with several other animal studies on diet-induced adiposity $[17,18]$, although to our knowledge this has not been described in this early stage before.

Cardiac function relies on adequate myocardial perfusion [21], for which microvascular function and responsiveness are important determinants. In this study we demonstrated impaired myocardial perfusion in mild adiposity, indicating that myocardial vascular dysfunction is an early phenomenon in diet-induced adiposity. Impaired vasodilatory responses have earlier been demonstrated in isolated hearts of obese mice fed a high fat diet for 8 weeks [22]. Moreover, rats exposed to high fat diet for 6 weeks had impaired microvascular responsiveness to adenosine administration [19]. In overweight, obese [3, $23]$ and morbidly obese [23, 24] subjects, endotheliumdependent myocardial perfusion responses to cold pressure test as well as the response to dipyridamole were blunted. These findings indicate impaired microvascular responsiveness, and disturbances in microvascular function have been related to hyperglycemia, dyslipidemia and insulin resistance $[25,26]$. Interestingly, in this study none of these were characteristics of our model, indicating that impairments of myocardial perfusion and function occur independently from metabolic defects in early stages of increased adiposity.

\section{Effect of intraoperative insulin treatment}

The increasing prevalence of overweight and obese patients that undergo surgery under anesthesia and the myocardial depression demonstrated in the described mouse model warrant treatment strategies to optimize perioperative cardiac function. Insulin has been shown to improve cardiac function in the setting of acute myocardial infarction, ischemia and reperfusion injury, sepsis and hemorrhagic shock $[9,10,27,28]$. In addition, perioperative insulin treatment was beneficial in cardiothoracic surgery $[11,29,30]$ although another study showed no benefit in cardiothoracic surgery [31]. Up to now, no studies have investigated how insulin influences perioperative myocardial depression in overweight and obesity, but we hypothesized a beneficial effect. While most studies have used glucose-insulin-potassium (GIK) as insulin treatment, in this study we used hyperinsulinemic euglycemic clamping for this purpose because maintenance of euglycemia eliminates the possible effects of hypo- and hyperglycemia on myocardial perfusion and function itself [32]. Furthermore, insulin itself and not glucose or potassium was shown to be the factor responsible for the beneficial effects of GIK in a previous study [33].
In the present study, insulin treatment improved intraoperative fractional shortening, but not load-independent end-systolic elastance in mildly adipose mice. In combination with decreased afterload and end-systolic pressure during hyperinsulinemia, this effect is most likely due to peripheral vasodilation, which is in concordance with previous findings [29, 34, 35]. Most studies that demonstrated a benefit of insulin on perioperative cardiac function have used load-dependent parameters such as cardiac index [35-37], while others who studied load-independent measures such as myocardial strain, showed no effect [31]. This supports our findings that insulin mainly affects loading conditions, but not loadindependent measurements of contractility. In this study, there was a trend towards improved diastolic function after insulin treatment, which is in agreement with earlier studies in lean animals [38]. We did however not observe an increase in myocardial perfusion upon insulin treatment, while insulin is known as a vasodilating agent in the myocardium [39]. Impaired vasodilation to insulin has however been demonstrated in other tissues in obesity, and may be consistent with the presence of microvascular dysfunction [16].

Taken together, these results suggest that intraoperative insulin treatment does not improve systolic function or myocardial perfusion, but decreases afterload and may improve ventricular relaxation when administered intraoperatively to mildly adipose mice with cardiodepression. While decreased systemic vascular resistance and afterload may reduce cardiac work load, it may also cause hypotension which could negatively affect tissue perfusion. However, we did not observe a significant effect on blood pressure and myocardial perfusion in this study. Although we observed no effects on systolic function, the trend towards a beneficial effect on diastolic function that we observed may on itself be relevant in the perioperative period. Diastolic dysfunction is an important risk factor in the perioperative period, as hemodynamic changes such as arrhythmias and tachycardia may affect diastolic filling, and existing diastolic dysfunction can acutely decompensate in the perioperative period [40].

\section{Conclusions}

In conclusion, mild adiposity is already associated with intraoperative myocardial depression in mice. Intraoperative insulin treatment improved echo-derived systolic function, decreased afterload and showed a trend towards improved diastolic function, but not load-independent measurements of systolic function or myocardial perfusion. These combined findings suggest that the early stage of adiposity without metabolic alterations already compromises cardiac function during anesthetized and mechanically ventilated conditions, and that 
intraoperative insulin treatment may be applied to modulate loading conditions and ventricular relaxation, but not to influence cardiac contractility.

\section{Authors' contributions}

CAB: data collection, data analysis and drafting of the manuscript. ECE, CB: study design, review of data analysis, editing of first draft and final manuscript. RAB: study design, review of data analysis, editing of final manuscript. RA: data collection. FSM: technical support with pressure-volume loops measurements, review of data analysis. IS: data collection. SAL: editing of the final manuscript. CEB: study design, data collection, review of data analysis, editing of first draft and final manuscript. All authors read and approved the final manuscript.

\section{Author details \\ ${ }^{1}$ Department of Anesthesiology, Institute for Cardiovascular Research, VU University Medical Center, De Boelelaan 1117, 1081 HV Amsterdam, The Netherlands. ${ }^{2}$ Department of Physiology, Institute for Cardiovascular Research, VU University Medical Center, Amsterdam, The Netherlands. ${ }^{3}$ Department of Anesthesiology, Catharina Hospital, Eindhoven, The Netherlands. ${ }^{4}$ Pulmo- nology, Institute for Cardiovascular Research, VU University Medical Center, Amsterdam, The Netherlands.}

\section{Acknowledgements}

None.

\section{Competing interests}

The authors declare that they have no competing interests.

\section{Availability of data and materials}

The datasets obtained and analyzed during the current study are available from the corresponding author on reasonable request.

\section{Ethics approval}

Animal experiments were approved by the Institutional Animal Care and Use Committee of the VU University (Amsterdam, the Netherlands. Permit number: ANES 12-04/ANES 13-04), and were conducted following the European Convention for the Protection of Vertebrate Animals used for Experimental and Other Scientific Purposes and the ARRIVE guidelines on animal research.

\section{Funding}

This work was supported by a start-up grant from the Institute for Cardiovascular Research (ICAR-VU) of the VU University Medical Center.

Received: 26 July 2016 Accepted: 13 September 2016

Published online: 20 September 2016

\section{References}

1. Scharwächter WH, Keet SWM, Stoecklein K, Loer SA, Boer C. Health risk factors in the anesthesia population. J Clin Anesth. 2016;32:33-9.

2. Alpert MA, Lavie CJ, Agrawal H, Kumar A, Kumar SA. Cardiac effects of obesity: pathophysiologic, clinical and prognostic consequences-a review. J Cardiopulm Rehabil Prev. 2016;36:1-11.

3. Schindler TH, Cardenas J, Prior JO, et al. Relationship between increasing body weight, insulin resistance, inflammation, adipocytokine leptin, and coronary circulatory function. J Am Coll Cardiol. 2006;47:1188-95.

4. Candiotti K, Sharma S, Shankar R. Obesity, obstructive sleep apnea, and diabetes mellitus: anesthetic implications. Br J Anaesth. 2009:103:i23-30.

5. Hodgson LE, Murphy PB, Hart N. Respiratory management of the obese patient undergoing surgery. J Thorac Dis. 2015;7:943-52.

6. Tzimas P, Petrou A, Laou E, et al. Impact of metabolic syndrome in surgical patients: should we bother? Br J Anaesth. 2015;115:194-202.

7. Bussey CT, de Leeuw AE, Lamberts RR. Increased hemodynamic adrenergic load with isoflurane anesthesia in type 2 diabetic and obese rats in vivo. Cardiovasc Diabetol. 2014;13:161.
8. Van den Brom CE, Boly CA, Bulte CS, van den Akker RF, Kwekkeboom RF, Loer SA, Boer C, Bouwman RA. Myocardial perfusion and function are distinctly altered by sevoflurane anesthesia in diet-induced prediabetic rats. J Diabetes Res. 2015. doi:10.1155/2016/5205631.

9. Holger JS, Dries DJ, Barringer KW, Peake BJ, Flottemesch TJ, Marini JJ. Cardiovascular and metabolic effects of high-dose insulin in a porcine septic shock model. Acad Emerg Med. 2010;17:429-35.

10. Soliman M. Insulin treatment before resuscitation following hemorrhagic shock improves cardiac contractility and protects the myocardium in the isolated rat heart. J Emerg Trauma Shock. 2015;8:144-8.

11. Fan Y, Zhang AM, Xiao YB, Weng YG, Hetzer R. Glucose-insulin-potassium therapy in adult patients undergoing cardiac surgery: a meta-analysis. Eur J Cardiothorac Surg. 2011;40:192-9.

12. Kilkenny C, Browne WJ, Cuthill IC, Emerson M, Altman DG. Improving bioscience research reporting: the ARRIVE guidelines for reporting animal research. PLoS Biol. 2010:8:e1000412.

13. van den Brom CE, Bulte CS, Kloeze BM, Loer SA, Boer C, Bouwman RA. High fat diet-induced glucose intolerance impairs myocardial function, but not myocardial perfusion during hyperaemia: a pilot study. Cardiovasc Diabetol. 2012;11:74.

14. Bulte CS, Slikkerveer J, Meijer Rl, et al. Contrast-enhanced ultrasound for myocardial perfusion imaging. Anesth Analg. 2012;114:938-45.

15. Burkhoff D, Mirsky I, Suga H. Assessment of systolic and diastolic ventricular properties via pressure-volume analysis: a guide for clinical, translational, and basic researchers. Am J Physiol Heart Circ Physiol. 2005;289:H501-12.

16. de Boer MP, Meijer RI, Richter EA, et al. Globular adiponectin controls insulin-mediated vasoreactivity in muscle through AMPKa2. Vascul Pharmacol. 2016:78:24-35.

17. Abdesselam I, Pepino P, Troalen T, et al. Time course of cardiometabolic alterations in a high fat high sucrose diet mice model and improvement after GLP-1 analog treatment using multimodal cardiovascular magnetic resonance. J Cardiovasc Magn Reson. 2015:17:95.

18. Soliman H, Nyamandi V, Garcia-Patino M, et al. Partial deletion of ROCK2 protects mice from high-fat diet-induced cardiac insulin resistance and contractile dysfunction. Am J Physiol Heart Circ Physiol. 2015;309:H70-81.

19. van Haare J, Kooi ME, Vink H, et al. Early impairment of coronary microvascular perfusion capacity in rats on a high fat diet. Cardiovasc Diabetol. 2015;14:150.

20. Mourmoura E, Chate V, Couturier K, et al. Body adiposity dictates different mechanisms of increased coronary reactivity related to improved in vivo cardiac function. Cardiovasc Diabetol. 2014;13:54.

21. Heusch $\mathrm{G}$. The regional myocardial flow-function relationship: a framework for an understanding of acute ischemia, hibernation, stunning and coronary microembolization. Circ Res. 2013;112:1535-7.

22. Gamez-Mendez AM, Vargas-Robles H, Rios A, Escalante B. Oxidative stress-dependent coronary endothelial dysfunction in obese mice. PLoS ONE. 2015;10:e0138609.

23. Quercioli A, Pataky Z, Montecucco F, et al. Coronary vasomotor control in obesity and morbid obesity: contrasting flow responses with endocannabinoids, leptin, and inflammation. JACC Cardiovasc Imaging. 2012:5:805-15.

24. Quercioli A, Montecucco F, Pataky Z, et al. Improvement in coronary circulatory function in morbidly obese individuals after gastric bypassinduced weight loss: relation to alterations in endocannabinoids and adipocytokines. Eur Heart J. 2013;34:2063-73.

25. Hink U, Li H, Mollnau H, Oelze M, et al. Mechanisms underlying endothelial dysfunction in diabetes mellitus. Circ Res. 2001;88:E14-22.

26. Tan KC, Ai VH, Chow WS, Chau MT, Leong L, Lam KS. Influence of low density lipoprotein (LDL) subfraction profile and LDL oxidation on endothelium-dependent and independent vasodilation in patients with type 2 diabetes. J Clin Endocrinol Metab. 1999;84:3212-6.

27. Fath-Ordoubadi F, Beatt KJ. Glucose-insulin-potassium therapy for treatment of acute myocardial infarction: an overview of randomized placebo-controlled trials. Circulation. 1997:96:1152-6.

28. Ma H, Zhang HF, Yu L, Zhang QJ, Li J, Huo JH, et al. Vasculoprotective effect of insulin in the ischemic/reperfused canine heart: role of Aktstimulated NO production. Cardiovasc Res. 2006;69:57-65. 
29. Howell NJ, Ashrafian H, Drury NE, et al. Glucose-insulin-potassium reduces the incidence of low cardiac output episodes after aortic valve replacement for aortic stenosis in patients with left ventricular hypertrophy: results from the Hypertrophy, Insulin, Glucose, and Electrolytes (HINGE) trial. Circulation. 2011;123:170-7.

30. Lazar HL. Enhanced preservation of acutely ischemic myocardium and improved clinical outcomes using glucose-insulin-potassium (GIK) solutions. Am J Cardiol. 1997;80:90A-3A.

31. Duncan AE, Kateby KB, Sarwar $\mathrm{S}$, et al. Hyperinsulinemic normoglycemia does not meaningfully improve myocardial performance during cardiac surgery: a randomized trial. Anesthesiology. 2015;123:272-87.

32. Van den Berghe G, Wouters PJ, Bouillon R, et al. Outcome benefit of intensive insulin therapy in the critically ill: insulin dose versus glycemic control. Crit Care Med. 2003;31:359-66.

33. Jonassen AK, Sack MN, Mjos OD, Yellon DM. Myocardial protection by insulin at reperfusion requires early administration and is mediated via Akt and p70s6 kinase cell-survival signaling. Circ Res. 2001;89:1191-8.

34. Quinn DW, Pagano D, Bonser RS, et al. Improved myocardial protection during coronary artery surgery with glucose-insulin-potassium: a randomized controlled trial. J Thorac Cardiovasc Surg. 2006;131:34-42.
35. Ranasinghe AM, Quinn DW, Pagano D, et al. Glucose-insulin-potassium and tri-iodothyronine individually improve hemodynamic performance and are associated with reduced troponin I release after on-pump coronary artery bypass grafting. Circulation. 2006;114:1245-50.

36. Lazar HL, Chipkin S, Philippides G, Bao Y, Apstein C. Glucose-insulin-potassium solutions improve outcomes in diabetics who have coronary artery operations. Ann Thorac Surg. 2000;70:145-50.

37. Sato H, Hatzakorzian R, Carvalho G, et al. High-dose insulin administration improves left ventricular function after coronary artery bypass graft surgery. J Cardiothorac Vasc Anesth. 2011;25:1086-91.

38. Zhang HF, Fan Q, Qian XX, et al. Role of insulin in the anti-apoptotic effect of glucose-insulin-potassium in rabbits with acute myocardial ischemia and reperfusion. Apoptosis. 2004;9:777-83.

39. Liu Z. Insulin at physiological concentrations increases microvascular perfusion in human myocardium. Am J Physiol Endocrinol Metab. 2007:293:E1250-5.

40. Pirracchio R, Cholley B, De HS, Solal AC, Mebazaa A. Diastolic heart failure in anesthesia and critical care. Br J Anaesth. 2007:98:707-21.

\section{Submit your next manuscript to BioMed Central and we will help you at every step:}

- We accept pre-submission inquiries

- Our selector tool helps you to find the most relevant journal

- We provide round the clock customer support

- Convenient online submission

- Thorough peer review

- Inclusion in PubMed and all major indexing services

- Maximum visibility for your research

Submit your manuscript at www.biomedcentral.com/submit 